dass es aus der Flüssigkeit herausragt, um das Platin mit Hülfe dieses Griffes von Zeit zu Zeit aus der Flüssigkeit entfernen zu kömnen. Die Fällung des Kupfers dauert bei gewöhnlicher Temperatur nicht über eine Stunde, jedoch nur 10 Minuten, wenn man in einer Schale von Platin arbeitet. Man erkennt das Ende der Reaction daran, dass ein Platindraht, mit welchem man das Pulver am Rande der Schale berührt, sich nicht mehr schwarz oder roth färbt, sondern blank bleibt. Man nimmt alsdann den Platindraht heraus, fügt dem Inhalte der Schale Tropfen für Tropfen soviel Essigsäure zu, um die Flüssigkeit klar zu erhalten, giesst die über dem reducirten Kupfer befindliche Flüssigkeit in ein graduirtes Gefäss von 100 oder $200 \mathrm{cc}$ Inhalt, wäscht Schale und Kupfer, fügt die Waschwasser der Hauptflüssigkeit zu und bringt das Volumen der Gesammtlösung auf 100 oder $200 \mathrm{cc}$. $10 \mathrm{cc}$ dieser Flüssigkeit werden in einem Kölbchen aus farblosem Glase mit dem doppelten bis dreifachen Volumen reiner Salzsäure zum Sieden erhitzt und mit Zinnchlorürlösung bis zu vollständiger Entfärbung titrirt. Den Titer der Zinnchlorürlösung stellt man mit Hülfe einer verdünnten Kupferlösung fest, von welcher $10 c c 0,04 g \mathrm{Kupfer}$ entsprechen.

Auf die an diese Arbeit sich anschliessenden Meinungsäusserungen verschiedener Forscher, insbesondere Kupferschläger*) und Weil**), kann hier wohl nur Bezug genommen werden. Bemerkenswerth aus denselben ist, dass metallisches Cadmium oder Eisen im Zinkstaub nach der Methode Weil's als Zink mitbestimmt werden würden.

Prüfung käuflicher Pikrinsäure. Nach A. H. Allen ${ }^{* * *}$ ) entsteht durch Einwirkung von Brom auf Mononitrophenol Dibromnitrophenol, auf Dinitrophenol Monobromdinitrophenol. Letzteres bildet sich auch unter Abspaltung von Salpetersäure aus Trinitrophenol, quantitativ falls die Einwirkung des Broms 12 Stunden lang dauerte, nicht aber im Verlaufe weniger Minuten bei gewöhnlicher Temperatur; in diesem Falle bindet Trinitrophenol kein Brom. Zur praktischen Verwerthung dieses Verhaltens bei Prüfung käuflicher Pikrinsäure misst Verfasser in zwei Stöpselflaschen je ein gleiches Volumen etwa 1 procentiges Bromwasser ab, fügt zu dem Inhalt der einen Flasche eine 1 procentige Lösung des

*) Bull. de Ia sac. chim. de Paris 47, 312 u. 657 .

**) Ebendaselbst 47, 877.

***) Journal of the Soc. of Dyers and Colorists 4, 84; durch Journal of the Society of Chemical Industry 7, 592.

Fresenius, Zeitschrift f. analyt. Chemie. XXX. Jahrgang. 
Untersuchungsobjectes, versetzt dann jede der beiden Flaschen mit Jodkalium im Ueberschuss and titrirt die Menge des abgeschiedenen Jods - welches ohne Einwirkung auf Mono-, Di- und Trinitro-Phenol ist mit Zehntel-Thiosulfat in bekannter Weise. Die Menge des substituirten Broms entspricht dem Gehalte der untersuchten Pikrinsäure-Probe an Mono- und Dinitrophenol.

Den Schmelzpunkt der Pikrinsäure bestimmt Allen, indem er Spuren der Probe auf Quecksilber in einer Schale erhitzt, welche mit einem Trichter bedeckt ist, durch dessen Röhre das Thermometer in das Bad eintaucht.

\section{Einen allgemeinen Gang zur Untersuchung von Schmierfett für} Eisenbahn-Achsen u. s. w. hat L. Archbutt*) in folgender Tabelle zusammengefasst :

$10 \mathrm{~g}$ des Untersuchungsobjectes werden in einem Becherglase mit Aether völlig zerrieben, die Mischung in einen Scheidetrichter gespült und wiederholt mit je $10 \mathrm{cc}$ Salzsäure von 1,10 specifischem Gewicht geschüttelt bis alle Metalle entfernt sind. (Eisen und Aluminium können nur durch starke Säure aufgenommen werden; Eisenchlorid geht aus seiner verdünnten sauren Lösung in Aether über.) Die zurückbleibende ätherische Lösung wird drei bis viermal mit je 10 cc Wasser gewaschen.

Die saure Lö- Die ätherischeLösung wird vorsichtig (urn Emulsionssung wird durch Ausschütteln mit Aether gereinigt (der Aether der Hauptlösung zugefügt) und darauf in einer Schale der freiwilligen Verdunstung überlassen; der dann getrocknete Rückstand wird wieder gelöst und auf $\mathrm{Me}$ talle in der gewöhnlichen Weise untersucht. bildung zu vermeiden) mit „Soda-Lösung. (einer Mischung aus $10 c c 10$ procentiger Aetznatron-Lösung, $5 c c$ methylirtem Spiritus ${ }^{* *}$ ) und $35 c c$ Wasser) geschüttelt.

Der alkalische Die ätherische Lösung wird verA uszug wird mit dunstet, das zurückbleibende Fett zur Aether gewaschen, Controle gewogen, alsdann verseift und und der Aether der die alkalische Lösung mit Aether ausHauptlösung zugefügt. Die gewaschene Lösung wird angesäuert, und mit Aether ausgeschüttelt. Diese ätherische Lösung hinterlässt nach dem Verdunsten die fetten Säuren u.den grösseren Theil vorhandenen Harzes. geschüttelt.

Die ätheri- Die alkalische sche Lösung Lösung wird angeenthält Kohlen- säuert und die dem Gewasserstoffe, Cho- halt des Schmiermittels lesterin, unver- an neutralen Fetten entseifbareBestand- sprechenden Säuren betheile, höhere stimmt. Etwa vorhanAlkohole etc. denes Harz findet sich zum Theil hier.

*) Journal of the Society of Chemical Industry $7,494$.

**) Denaturirter Spiritus der Engländer. 